\title{
THAUMA E PENSAR BEM NA EDUCAÇÃO INFANTIL
}

\section{THAUMA AND THINK WELL IN EARLY CHILDHOOD EDUCATION}

\author{
Marcos Antônio Lorieri \\ Docente do Programa de Pós-Graduação em Educaçáo da Universida- \\ de Nove de Julho (PPGE-Uninove) - São Paulo - SP - Brasil \\ lorieri@sti.com.br
}

Eduardo Gasperoni de Oliveira

Mestre em Educação pela Universidade Nove de Julho - São Paulo - SP - Brasil

egopsicopedagogo@gmail.com

\begin{abstract}
Resumo: O texto é decorrência de pesquisa cujo tema foi: Filosofia e Educação para Pensar Bem na Educação Infantil, que teve como foco as possíveis contribuiçóes da proposta do Programa de Filosofia para Crianças-Educação para o Pensar de Matthew Lipman para o estabelecimento de procedimentos pedagógicos que favoreçam a manutenção e o desenvolvimento da natural curiosidade das crianças em torno do conhecer. $\mathrm{Na}$ Educação Infantil não há, costumeiramente, preocupação e procedimentos que visem a alimentar essa natural curiosidade manifestada pelas expressóes de admiração e de espanto (thauma, como o definiram Platão e Aristóteles) das crianças, curiosidade que é impulsionadora da busca por explicaçóes e entendimentos. A questão central, aqui, é: em que medida práticas reflexivas iniciais a partir das perguntas das crianças, de acordo com o proposto por Lipman, podem contribuir para uma educação para o pensar bem na Educação Infantil? O texto apresenta consideraçôes e proposiçóes a respeito do que se pode fazer na Educação Infantil. A referência teórica principal são as ideias de Lipman, acrescidas das de outros pensadores como Paulo Freire, Karl Jaspers, Hannah Arendt, Darcísio Muraro e John Dewey. Trata-se de pesquisa bibliográfica que utiliza como categorias analíticas: curiosidade infantil (thauma), pensar bem, diálogo e educação para pensar bem.
\end{abstract}

Palavras-Chave: Curiosidade Infantil. Diálogo. Educação Infantil. Pensar Bem. Thauma.

Abstract: The text is the result of a research whose theme was: Philosophy and Education to Think Well in Early Childhood Education, which focused on the possible contributions of the proposal of the Philosophy Program for Children-Education for the Thinking of Matthew Lipman for the establishment of pedagogical procedures that favor the maintenance and development of the natural curiosity of the children around the know. In Childhood Education, there is usually no concern and procedures aimed at nourishing this natural curiosity manifested by the expressions of admiration and astonishment (thauma, as Plato and Aristotle defined it) of children, a curiosity that drives the search for explanations and understandings. The central question here is: to what extent do initial reflective practices based on children's questions, as proposed by Lipman, contribute to an education for thinking well in Early Childhood Education? The text presents considerations and propositions regarding 
what can be done in Early Childhood Education. The main theoretical reference is Lipman's ideas plus those of other thinkers such as Paulo Freire, Karl Jaspers, Hannah Arendt, Darcísio Muraro and John Dewey. It is a bibliographical research that uses as analytical categories: children's curiosity (thauma), think well, dialogue and education to think well.

Keywords: Children's Curiosity. Dialogue. Child Education. To Think Well. Thauma.

\section{Introduçáo}

Preocupado com o desempenho e com o desenvolvimento cognitivo de crianças e jovens, Matthew Lipman concebeu o "Programa de Filosofia para Crianças" na década de 1960, visando primordialmente auxiliá-los a pensar bem. $\mathrm{O}$ objetivo essencial dessa proposta refere-se ao náo deixar perecer nas crianças e jovens as questóes originadas do "espanto" ou da admiração em relação ao mundo e seus mistérios (que os filósofos gregos denominavam de thauma) e incentivá-los à busca de respostas a elas, nos moldes em que o faz a Filosofia. Isso, segundo ele, provoca uma maneira de pensar mais exigente, ou seja, reflexiva, crítica e criativa, favorecendo o cultivo e o fortalecimento de habilidades de pensamento e, portanto, o pensar bem. Daí a denominação de sua proposta de "Programa de Filosofia para Crianças - Educação para o Pensar".

É recorrente no discurso filosófico afirmar que a atitude filosófica remete ao indagar, isto é, ao perguntar o quê, o como e o porquê das coisas, valores ou ideias.

Nesse sentido, a atitude filosófica tem início quando tais indagaçôes se dirigem ao mundo e às relaçôes que nele ocorrem, bem como às relaçóes que os seres humanos estabelecem com ele e entre si. A produção de respostas a essas indagaçóes exige capacidades especiais que estão presentes no filosofar e no produzir ciência, tidas como maneiras mais bem elaboradas de pensar e, por consequência, de conhecer. A iniciação progressiva de crianças nessas maneiras de pensar pode ser um caminho produtivo de desenvolvimento do pensar bem delas.

Pretende-se, aqui, apresentar a proposta de iniciação filosófica de crianças, tal como concebida por Matthew Lipman, e ideias a respeito das possibilidades de trazer elementos dessa proposta, com as devidas adequaçóes, para a Educação Infantil. 


\section{Thauma e pensar bem}

Thauma é palavra grega derivada do verbo thaumazein, que tem sido traduzido por admirar-se. Thauma seria admiração ou espanto frente a algo que desperta nossa atenção de maneira especial, seja pelo inusitado que carrega, seja por provocar alguma estupefaçáo: "Trata-se de um estado que nos acomete quando nos defrontamos com algo estranho por ser "thaumaston", extraordinário, admirável. No diálogo Teeteto, Platão refere-se a essa admiração como um pathos, um estado interior que sentimos quando algo nos arrebata”, diz Von Zuben (2011, p. 1). É de Platão ainda, no mesmo diálogo, esta afirmação: "Nosso olho nos faz participar do espetáculo das estrelas, do sol e da abóbada celeste. Este espetáculo nos incitou a estudar o universo inteiro. De lá nasce para nós a filosofia, o mais precioso bem concedido pelos deuses à raça dos mortais." Ou: "[...] pois a admiração é a verdadeira característica do filósofo. Não tem outra origem a Filosofia. Ao que parece, não foi mal genealogista quem disse que Íris era filha de Taumante." (PLATÃO, 2001, p. 55)

Depois de Platão, Aristóteles (1969, p.40) também se refere ao thau$m a$, ou à admiração, como o sentimento originário do filosofar na sua obra Metafísica: "É a admiração que leva os homens a filosofar. Eles admiram-se das coisas estranhas com que esbarram; depois avançam pouco a pouco e começam por questionar as fases da lua, o movimento do sol e dos astros e, por fim, a origem do universo inteiro."

Paulo Freire utiliza com frequência essa palavra. Ele a registra com destaque em alguns textos desta maneira: "ad-mirar". Mirar é olhar e o "ad" significa "para" - admirar é olhar para algo de maneira intrigante e curiosa. Diz ele a respeito da admiração:

Expliquemo-nos: a posição normal do homem no mundo, como um ser da ação e da reflexão, é a de "ad-mirador" do mundo. [...] 'Ad-mirar' a realidade significa objetivá-la, apreendê-la como um campo de sua ação e reflexão. Significa penetrála, cada vez mais lucidamente, para descobrir as inter-relaçóes verdadeiras dos fatos percebidos. (FREIRE, 1975, p. 31) 
Ao acolher a provocação da admiração, o ser humano fica incentivado a perguntar e a ir à busca de respostas para suas perguntas. A admiração, ou o espanto, ou o thauma, é uma posição normal do ser humano no mundo. É uma posição especialmente forte das crianças, como também é destacado por Lipman, que a aponta como semelhante à admiração dos filósofos ao afirmar que o que as crianças e os filósofos têm em comum é a capacidade de maravilhar-se com o mundo. As ideias de Lipman a respeito dessa caraterística "admirativa" - não apenas das crianças, mas nelas muito intensa - estão expressas em várias obras e, de maneira mais incisiva no livro Filosofia na sala de aula (1994), escrito em coautoria com Oskanian e Sharp, em especial no capítulo 3, no qual, ao indicar ser essa uma característica própria dos seres humanos e, portanto, das crianças, aponta para a necessidade da exemplaridade admirativa por parte dos adultos nas suas relaçôes com elas, o que vale, obviamente, para os professores, especialmente os da Educação Infantil. Assim se referem esses autores ao termo:

Para muitos adultos a experiência de se admirar e refletir nunca exerceu nenhuma influência sobre suas vidas. Assim, estes adultos deixaram de questionar e de buscar os significados da sua experiência e, finalmente, se tornaram exemplos da aceitação passiva que as crianças acatam como modelos para sua própria conduta. Desse modo a proibição de se admirar e de questionar se transmite de geração para geração.

Em pouco tempo, as crianças que agora estão na escola serão pais. Se pudermos, de algum modo, preservar o seu senso natural de deslumbramento, sua prontidão em buscar o significado e sua vontade de compreender o porquê de as coisas serem como são, haverá uma esperança de que ao menos essa geração não sirva aos seus próprios filhos como modelo de aceitação passiva. (LIPMAN, OSKANIAN; SHARP, 1994, p. 55)

Essas ideias aproximam-se do que diz Karl Jaspers (apud VERGEZ; HUISMAN, 1984, p. 385-387) no livro Introdução à Filosofia:

Um sinal admirável do fato de que o ser humano encontra em si a fonte de sua reflexão filosófica está nas perguntas das crian- 
ças. Ouvem-se frequentemente de seus lábios as palavras cujo sentido mergulha diretamente nas profundezas filosóficas. Eis alguns exemplos:

Um diz com espanto: "tento sempre pensar que sou um outro, e eu sou, apesar disso, sempre eu”. Ele atinge assim ao que constitui a origem de toda certeza, a consciência do ser no conhecimento de si. Ele permanece tolhido diante do enigma do eu, este enigma que nada permite resolvê-lo. Ele estaciona aí, diante deste limite, ele interroga.

Um outro que escutava a história da gênese: "No começo Deus criou o céu e a terra...", logo perguntou: "Que havia então antes do começo?” Ele descobria assim que as questóes se engendram até $\mathrm{o}$ infinito, que o entendimento não conhece limites em suas investigaçôes e que, para ele, não existe resposta verdadeiramente concludente.

Uma 'menina faz um passeio: à entrada de uma clareira, contam-lhe histórias de duendes que ali dançam à noite. "Mas, no entanto, eles não existem... "Falam-lhe, então, de coisas reais, fazem-na observar o movimento do sol, discute-se a questâo de saber se é o sol que morre ou a terra que gira. Criam-se razóes para acreditar na forma esférica da terra e em seu movimento de rotação. Mas isto não é verdade, diz a menina batendo o pé, a terra não gira. "Só acredito no que vejo".

Após essas citaçóes de falas das crianças, Jaspers na continuidade do texto acima mencionado, afirma o seguinte:

Poder-se-á constituir toda uma filosofia infantil colecionando-se passagens como estas. Alegar-se-á talvez que as crianças repetem o que ouvem de seus pais e de outros adultos; esta objeçâo é sem valor quando se trata de pensamentos tâo sérios. Dir-se-á ainda que estas crianças não desenvolvem a reflexão filosófica e que, portanto, não pode haver aí entre elas senão o efeito de um acaso. Negligenciar-se-ia entáo um fato: elas possuem frequentemente uma genialidade que se perde logo que se tornam adultos. Tudo se passa como se, com os anos, nós 
entrássemos na prisão das convençóes e das opiniôes correntes das dissimulaçóes e dos preconceitos, perdendo, no mesmo golpe, a espontaneidade da criança, receptiva a tudo o que traz a vida que se renova para ela a todo instante. Ela sente, vê, interroga, e depois, tudo isso logo se lhe escapa. Ela deixa cair no esquecimento o que foi um instante a ela revelado e mais tarde ficará surpresa quando lhe contarem o que dissera e perguntara. (Id.Ibid)

Ou seja, aquilo que é natural no ser humano, presente portanto, na admiração ou no maravilhamento infantil (no thauma), pode se perder se não for alimentado ao longo de sua formação. É o que dizem, em citação feita anteriormente, Lipman, Oskanian e Sharp, ao justificarem a iniciação de crianças e jovens no filosofar para que náo cresçam com posturas passivas, e não indagativas, em relação ao mundo, especialmente em relação às respostas que encontram prontas nos ambientes nos quais se inserem, como muitas vezes ocorre com os adultos com os quais convivem. A capacidade de maravilhamento das crianças pode se perder à medida que caminham para a vida adulta e, para que isso náo ocorra, é necessária uma educação que alimente essa atitude fundamental e impulsionadora da busca de conhecimentos e de significados, tão necessários a todas as pessoas.

As crianças não desenvolvem uma reflexão como as dos filósofos a partir das questóes que se colocam, isso é óbvio, mas muitas de suas questóes se assemelham às dos filósofos e despertam nelas um primeiro processo de pensar que, se estimulado ao longo dos anos, poderá ajudálas no desenvolvimento do desejado pensamento reflexivo e crítico. Elas podem ampliar e desenvolver seus questionamentos e sua maneira de pensar de tal modo que o filosofar faça parte de suas vidas, auxiliandoas no enfrentamento das questóes que a sua admiração, alimentada por uma educação filosófica, lhes coloca, auxiliando-as no tratamento cada vez mais reflexivo e crítico dessas questóes. É isso o que diz, por exemplo, Muraro (2012, s/p)

Os filósofos levam esta capacidade de maravilhamento às últimas consequências, descobrindo e investigando os problemas 
da experiência humana. Tais problemas giram em torno de conceitos centrais, comuns e controversos em nossa experiência. Desta forma, os filósofos conseguem criar e reconstruir conceitos e buscar formas de explicação mais abrangentes para os problemas da vida. As crianças ficam intrigadas com os mesmos conceitos problemáticos, ou seja, colocam-se questóes sobre a verdade, as regras, a justiça, a realidade, a bondade, a amizade, etc. Necessitam, portanto, de uma educaçâo filosófica para tratar destas questóes e, simultaneamente, aprender os processos do raciocínio e do julgamento.

O que nos faz pensar são os problemas que encontramos no decorrer de nossa existência. Eles criam em nós uma situação de estupefaçáo ou de ad-miraçâo, ou ainda de 'maravilhamento' - ou seja, o thauma dos gregos. Para enfrentar essa situação dispomos da capacidade de pensar que é acionada por esses problemas e pelo acolhimento deles como objetos de nossa atenção pensante. O thauma, ou a situação problemática com a qual nos deparamos, é o motor acionador do pensar. Essa é a relação básica do thauma com o pensamento: o de ser o agente desencadeador do pensar.

Nessa direção, caminham afirmações, por exemplo, de Hannah Arendt (1972, p. 41) quando diz, em Entre o passado e o futuro, que "[...] meu pressuposto é que o pensamento emerge de incidentes da experiência viva e a eles deve permanecer ligado, já que são os únicos marcos por onde pode obter orientação [...]”; e, em $A$ vida do Espírito, reforça essa ideia ao afirmar: "as questóes levantadas por nossa sede de conhecimento derivam de nossa curiosidade sobre o mundo, nosso desejo de investigar qualquer coisa que seja dada ao nosso aparelho sensorial"1 (ARENDT, 1992 , p. 46). Incidentes e questôes oriundas da natural curiosidade humana, provocam a admiração e levam à busca de entendimento e compreensão. Trata-se da curiosidade que é muito realçada como um aspecto especialmente próprio das crianças. Infelizmente, porém, essa característica profundamente humana é pouco alimentada e desenvolvida. $\mathrm{O}$ thauma fica esmorecido. Dado que ele é, como já afirmado, o motor desencadeador do pensar, urge preservá-lo e, além disso, desenvolver atividades que respondam aos desejos que ele desencadeia, ou seja, alimentar 
atividades de busca de respostas às indagações que ele suscita. Essa busca é a investigação. E para realizá-la de maneira a que produza os melhores resultados possíveis em entendimentos e explicações, é necessário que sejam desenvolvidas qualidades ou competências no pensar capazes de ajudar na busca das respostas desejadas.

Trata-se de desenvolver o pensar bem para que as indagações surgidas das provocaçóes do thauma possam ter prosseguimento no esforço de compreensão cada vez mais amplo ao longo da vida. $\mathrm{O}$ começo desse percurso está na infância e a Educação Infantil tem um papel importante também nessa direção.

\section{A busca do desenvolvimento do pensar bem na Educaçáo Infantil}

Lipman (1995) concebe a criança como espontaneidade, curiosidade, inquietude e propensão ao diálogo, no qual, além de trocar com seus pares o que apreende de suas admiraçóes e do pensar sobre ou a partir delas, troca caminhos de como buscar respostas às suas perguntas. Espontaneidade, curiosidade, inquietude e diálogo investigativo são características do filosofar e, por isso, Lipman propõe que se convide crianças a desenvolver, ao menos nas instituiçôes educacionais formais, conversas questionadoras na forma de diálogos investigativos.

Com vistas à concretização de suas ideias, desenvolveu uma proposta que denominou Programa de Filosofia para Crianças. A essa denominação pode-se juntar a ideia de "educação para pensar bem". Nos termos de Lipman, Oskanian e Sharp (1994, p. 92):

O mérito de Filosofia para crianças está em permitir que a aula se torne um fórum para ventilar assuntos relevantes para os problemas das próprias crianças, assuntos suficientemente variados para que o apelo náo se reduza aos aspectos manipuladores da inteligência infantil, mas alcance também os aspectos contemplativos e criativos. 
Nossas escolas, muitas vezes, manipulam a inteligência infantil oferecendo às crianças apenas respostas prontas às suas indagaçôes e, pior ainda, oferecendo respostas prontas a indagaçóes que elas nem sequer se colocam. Esse tipo de escola tem um objetivo assumido historicamente que é o de adaptação das novas geraçóes a um tipo de mundo que aí está e que é conveniente aos adultos que nele já estão, especialmente aos que detêm poder sobre os demais.

Lipman, $(1990,1995)$ na continuidade do pensamento educacional de Dewey, propóe que se levem em conta as perguntas das crianças originadas de sua admiração em relação ao mundo no qual chegam, originadas, portanto, do thauma; e que a educação parta daí provocando as crianças para a busca de respostas, com a necessária ajuda dos adultos com os quais convivem. Busca de respostas às indagaçóes que surjam de suas vivências, ou dos "incidentes da experiência viva", no dizer de Arendt (1972, p. 41), ou, ainda, da "posição normal do homem no mundo" que é de "ad-mirador" do mundo", nos termos de Paulo Freire (1975, p. 31). O que Lipman, Oskanian e Sharp (1994, p. 92) propóem, na citação acima, é que no caso das escolas, seja em que nível for, as aulas se tornem "um fórum para ventilar assuntos relevantes para os problemas das próprias crianças." Relevantes pelo fato de serem oriundos da sua "ad-miração" (Freire, 1975, p. 31) ou do impacto dos "incidentes da experiência viva." (Arendt, 1972, p. 41) Esses assuntos relevantes são os conteúdos a serem objeto da investigação dialógica proposta por Lipman, assim como o são para Freire, por exemplo, nos círculos de cultura. Pois são eles os conteúdos com os quais o pensamento tem sempre que se haver.

Lipman (1995, p. 29) partiu do princípio de que era preciso substituir o "modelo tradicional de educação", baseado apenas na transmissão de conhecimentos, na autoridade do professor e na noção de aprendizagem apenas como absorção de informaçôes ${ }^{2}$ pelo modelo da educação para o pensar, ou modelo reflexivo da prática educativa crítica.

Nesse modelo educacional não cabe à escola ensinar apenas o produto das investigaçôes, mas ensinar, também, os procedimentos investigativos e ao desenvolvimento dos processos do pensar bem e, por consequência, das habilidades necessárias a esse pensar bem. Isso, de maneira especial, precisa merecer a atenção dos educadores na Educação Infantil. 
Lipman aponta diversas dessas habilidades de pensamento que, a par de outras, devem ter seu desenvolvimento estimulado desde a Educação Infantil. Veja-se o que diz dessas habilidades em A filosofia vai à escola (1990, especialmente às páginas 47-53; 80-81; 227-241) e em O pensar na educação (1995, p. 65-76). Esta última obra trata especificamente das questóes relativas à necessidade de uma educação para o pensar bem no âmbito das escolas; nela ele detalha o entendimento do que sejam habilidades de pensamento, bem como o entendimento de cada uma delas reunidas nos seguintes grupos: a) Habilidades de Investigação - envolvem as habilidades de observar, perguntar, supor respostas às perguntas (formular hipóteses), buscar comprovações a essas suposições e expor as conclusóes às quais se chega; b) Habilidades de Raciocínio - dizem respeito aos processos de inferência, ou aos processos de produçáo de conclusôes válidas a partir de certas relaçóes entre conhecimentos ou informaçóes prévias. Capacidades como as de formular questôes, produzir juízos, estabelecer relaçóes entre afirmaçóes (juízos), inferir, detectar pressuposições subjacentes, identificar similaridades e diferenças, comparar e contrastar, construir e criticar analogias e argumentar ou dar razóes; c) Habilidades de Formação de Conceitos - habilidades de representar mentalmente as características básicas de algo; de identificar, nas palavras, a ideia de algo (ou o significado), e outras daí decorrentes como definir e explicar. d) Habilidades de Tradução - capacidade de dizer algo que já foi dito, por meio de outras palavras ou outras formas de expressão, conservando o mesmo significado. São habilidades inerentes à interpretação, à paráfrase e outras.

Para Lipman, essas habilidades e o trabalho educativo com elas, especialmente nas conversas investigativas das crianças (diálogo investigativo), são pré-requisitos para o desenvolvimento do pensar bem. Por conseguinte, precisam estar disponibilizadas às crianças já desde a Educação Infantil. As conversas investigativas (o diálogo investigativo) podem ocorrer, por exemplo, nas rodas de conversa utilizadas em muitas instituiçóes de Educação Infantil. Aliás, as rodas de conversa merecem destaque no documento oficial de orientações para a Educação Infantil no Brasil, publicado em 1998, denominado Referencial Curricular para a Educação Infantil (RCNEI). Dele foi extraído o seguinte: 
A roda de conversa é o momento privilegiado de diálogo e intercâmbio de ideias. Por meio desse exercício cotidiano as crianças podem ampliar suas capacidades comunicativas, como a fluência para falar, perguntar, expor suas ideias, dúvidas e descobertas, ampliar seu vocabulário e aprender a valorizar o grupo como instância de troca e aprendizagem. A participaçáo na roda permite que as crianças aprendam a olhar e a ouvir os amigos, trocando experiências. Pode-se, na roda, contar fatos às crianças, descrever ações e promover uma aproximaçáo com aspectos mais formais da linguagem por meio de situações como ler e contar histórias, cantar ou entoar cançôes, declamar poesias, dizer parlendas, textos de brincadeiras infantis etc. (BRASIL, 1998, p. 138)

São dizeres que se aproximam muito estreitamente das ideias de Lipman, que indica, para todos os níveis da educação formal, incluindo a Educação Infantil, a metodologia da comunidade de investigação que se realiza em círculos, ou rodas de conversa, que segundo ele não podem ser rodas de "meras conversas" e sim de conversas "que possuem um compromisso com os procedimentos da investigaçáo, com a busca responsável das técnicas que pressupóem uma abertura para a evidência e para a razão.” (LIPMAN; OSKANIAN; SHARP, 1994, p. 72)

Essa sua preocupação relaciona-se a uma crítica que o RCNEI (BRASIL, 1998, p. 138) também faz a certas maneiras de conduzir as rodas de conversa:

Apesar de serem organizadas com a intenção de desenvolver a conversa, se caracterizam, em geral, por um monólogo com o professor, no qual as crianças são chamadas a responder em coro a uma única pergunta dirigida a todos, ou cada um por sua vez, em uma ação totalmente centrada no adulto.

Por certo, para Lipman, não é disso que se trata. Ele sugere que os desencadeadores desse diálogo investigativo sejam, ou textos preparados a propósito para provocar a admiraçáo das crianças em relaçáo a certos aspectos da realidade, ou relatos das próprias crianças a respeito de situaçôes vividas ou a respeito de objetos, fatos ou ocorrências que observaram 
e que chamaram sua atenção, ou histórias lidas ou escutadas por elas, a partir das quais levantem indagaçóes (perguntas) provocadas pelo espanto, pela admiração, pela estupefação, pelo thauma que esses objetos, fatos ou ocorrências nelas provocaram. Quando as perguntas carregam algum conteúdo filosófico, pensa-se, de acordo com seu entendimento, que isso possa ser uma iniciaçáo produtiva do filosofar nas crianças, a demandar desenvolvimentos futuros que se concretizem em alguma formação filosófica, sempre necessária.

Independentemente da perspectiva de alguma formação filosófica futura, o trabalho educativo na Educação Infantil, partindo das ideias de Lipman relativas à metodologia da comunidade de investigação, pode contribuir efetivamente para que as crianças sejam progressivamente capazes de:

- Dizer exatamente o que pretendem dizer.

- Escutar e entender o que os outros dizem.

- Concordar ou discordar com ou do que ouvem.

- Dar razóes para suas afirmativas ou para suas concordâncias ou discordâncias.

- Rebater, com argumentos, as discordâncias dos outros em relação a seus pontos de vista.

- Corrigir-se, quando convencidos pelos outros de que seus pontos de vista não são ou verdadeiros ou completos.

- Fazer análises e sínteses a todo o momento.

- Elaborar mentalmente tudo isso e ser capaz de expressar verbalmente todo esse conjunto de elaboraçôes.

Além disso, há aspectos éticos importantes na participação em uma comunidade de investigação em que o diálogo, e não a disputa, é a regra:

- Aprende-se a respeitar os pontos de vista dos outros.

- Aprende-se que o próprio ponto de vista tem o mesmo valor e peso do dos outros.

- Aprende-se a respeitar a vez dos outros e a exigir respeito pela própria vez.

- Aprende-se a respeitar regras combinadas. 
- Aprende-se que regras podem ser discutidas e modificadas, mas que são necessárias para a vida em comum.

- Aprende-se que somos todos iguais.

- Aprende-se que somos todos igualmente dignos de respeito.

O valor do diálogo, em qualquer circunstância, mas especialmente em educação, é defendido por Paulo Freire quando propóe uma educação dialógica, expressão marcante do seu pensamento pedagógico, como já afirmado. Ele indica o diálogo como caminho de construção do conhecimento e como caminho de promoçáo dos participantes do processo educacional a verdadeiros sujeitos do seu saber. Em Extensão ou Comunicação? (1975) - obra na qual o próprio título já propóe a discussão a respeito do que escolher: comunicação (diálogo) ou extensão (ensino de verdades prontas) -, Freire (1975, p. 43) tem expressóes como estas:

Ser dialógico é não invadir, é não manipular e não sloganizar. Ser dialógico é emprenhar-se na transformação constante da realidade. Esta é a razáo pela qual, sendo o diálogo o conteúdo da forma de ser, própria à existência humana, está excluído de toda relação na qual alguns homens sejam transformados em "seres para outro" por homens que são falsos “seres para si”. É que diálogo não pode travar-se numa relação antagônica. O diálogo é o encontro amoroso dos homens que, mediatizados pelo mundo, o "pronunciam", isto é, o transformam e, transformando-o, o humanizam para a humanização de todos.

Lipman propóe o diálogo como o cerne da metodologia da comunidade de investigação do Programa de Filosofia para Crianças e Educação para Pensar Bem. Trata-se de uma metodologia que tem como início a apresentação de perguntas das crianças, originadas de sua natural curiosidade, ou de sua natural admiração em relação a tudo o que chama sua atenção. Provocadas a perguntar, é-lhes proposto um esforço por pensar respostas. Ao explicitarem suas repostas, são convidadas a concordarem ou não com as respostas dadas e a apresentarem razóes para suas concordâncias ou discordâncias. Aos autores das repostas lhes é solicitado, à vista das concordâncias e discordâncias e à vista dos argumentos, a se reportarem 
aos que se pronunciaram sobre suas colocaçóes dizendo-lhes, também, se concordam, ou não e porquê. Esse movimento inicial provoca o diálogo, ou a troca de ideias a respeito do tema em pauta, motivada, essa troca, pelas perguntas, pelas respostas e pelos argumentos.

O processo desencadeado, se bem conduzido, é um verdadeiro processo coletivo de investigação com vistas a auxiliar cada membro do grupo a produzir, talvez não uma reposta final, mas aproximaçôes a possíveis respostas mais seguras, especialmente pela argumentação desenvolvida. $\mathrm{Na}$ visão de Lipman, o objetivo não é o consenso e, sim, a produção de um caminho que cada qual, membro do grupo, trilhará por conta própria. Eventualmente haverá consensos. Algo muito importante, além de outros resultados, é buscado nesse processo: alimentar a curiosidade, ou seja, a admiração natural das crianças, o seu thauma. Pois, dizem Lipman, Oskanian; Sharp (1994, p. 55), as crianças não são incentivadas à "perguntação" por adultos que também não o foram e lhes são exemplos de passividade frente ao mundo, conforme citação feita anteriormente, da qual é retomado o seguinte excerto: "Assim, estes adultos deixaram de questionar e de buscar os significados da sua experiência e, finalmente, se tornaram exemplos da aceitação passiva que as crianças acatam como modelos para sua própria conduta. Desse modo a proibição de se admirar e de questionar se transmite de geração para geração."

Freire propóe o mesmo, ressalvadas sempre as diferenças de posturas políticas de ambos, ao colocar o diálogo como o coração de sua proposta educacional, pode-se dizer assim. Diálogo que se alimenta da proposição de que se perguntem admirativamente sobre o seu mundo e sobre si mesmos. É o que ele diz:

Colocar este mundo humano como problema para os homens significa propor-lhes que "ad-mirem", criticamente, numa operação totalizada, sua ação e a de outros sobre o mundo. Significa "re-ad-mirá-lo", através da "ad-miração" anterior, que pode ter sido feita ou realizada de forma ingênua, não totalizada. Desta maneira, na "ad-miraçáo" do mundo "ad-mirado", os homens tomam conhecimento da forma como estavam conhecendo, e assim reconhecem a necessidade de conhecer melhor. Aí reside 
toda a força da educação que se constitui em situação gnosiológica. (FREIRE, 1975, p. 83-84)

A busca aqui é a de um pensar bem que somente pode ocorrer em um processo educativo que realmente seja um encadeamento de situaçôes gnosiológicas entendidas como situaçôes nas quais todos os envolvidos buscam saber mais a respeito de si e de seu mundo partindo dessa necessária problematização causada pela "ad-miração" ou pelo thauma.

\section{Consideraçóes Finais}

A partir do que foi dito, percebe-se que aquilo que, no senso comum, é apontado até com certa graça como sendo específico das crianças, sua curiosidade, nada mais é do que uma qualidade fundamental dos seres humanos que os dispóe a todo o processo de busca de compreensão de si mesmos e da realidade da qual participam. Trata-se dessa qualidade ou capacidade que pode ser denominada admiração ou estupefação frente à vida, frente ao que em nós ocorre e a muitas outras ocorrências do mundo. Trata-se daquilo que os filósofos gregos nominaram thauma.

Não só: pode-se perceber que essa qualidade deve ser desenvolvida nas pessoas desde o mais cedo possível, cabendo à Educação Infantil o cultivo inicial não apenas do thauma, do espanto, do admirar-se, mas também das habilidades de pensamento necessárias para que, desde crianças, possam pensar as questóes que o thauma suscita e possam, ao pensá-las bem, pensar também as soluçóes que dão a essas questóes; e, ainda, pensar, de maneira reflexiva e crítica, as soluçóes que encontram já dadas no ambiente cultural do qual participam.

Aventou-se aqui a possibilidade de utilização das ideias de Matthew Lipman constantes do seu Programa de Filosofia para Crianças-Educação para o Pensar Bem e de suas obras. Pensar tal possibilidade decorre da convicção dos autores deste artigo, baseada na análise das ideias de Lipman e em experiências práticas em escolas, bem como de que aí se encontram caminhos promissores de uma educação voltada para o desenvolvimento do pensar bem. Esses caminhos merecem análise crítica dos educadores e, principalmente, a partir dessa análise, espera-se que sejam encontrados 
caminhos cada vez melhores para a realização deste desejo que a todos deveria mover: o desejo de que as pessoas pensem bem. Pois, se isso não é suficiente para uma vida boa, por certo que é necessário.

\section{Notas}

1 Hannah Arendt dedica a primeira parte da obra A vida do Espírito, ao pensar. Esta parte é assim denominada: Volume 1- O pensar. Nos limites deste texto não é possível uma mais ampla apresentação de suas ideias. Pensamos que vale a pena serem lidas, pois, sáo frequentes suas afirmaçôes a respeito dos incidentes que provocam nosso pensar.

2 Paulo Freire, tanto em Pedagogia do oprimido (1987) quanto em Extensáo ou comunicação? (1975), aponta insistentemente para a necessidade da superação do que denomina "educação bancária" (em Pedagogia do oprimido) e do que denomina "extensão de informes" (em Extensão ou comunicação? ). Em ambas as obras propóe como caminho uma educação dialógica, assim como Lipman propóe a metodologia da comunidade de investigação, cujo cerne é o diálogo, para a superação do "modelo tradicional de educação".

\section{Referências}

ARENDT, Hannah. Entre o passado e o futuro. Trad. Mauro W. Barbosa de Almeida. São Paulo: Perspectiva, 1972. . A vida do espírito: o pensar, o querer, o julgar. 3. ed. Rio de Janeiro: Relume

Dumará, 1992.

ARISTÓTELES, Metafísica. Trad. Leonel Vallandro. Porto Alegre: Globo, 1969.

BRASIL. MINISTÉRIO DA EDUCAÇÃO E DO DESPORTO. Secretaria de Educação Fundamental. Referencial curricular nacional para a educação infantil I Ministério da Educaçáo e do Desporto, Secretaria de Educação Fundamental. — Brasília: MEC/SEF, 1998.

FREIRE, Paulo. Extensão ou comunicação? 2. ed. São Paulo: Paz e Terra, 1975. . Pedagogia do oprimido. 17. ed. Rio de Janeiro, Paz e Terra, 1987.

LIPMAN, Matthew. A filosofia vai à Escola. São Paulo: Summus, 1990. . O pensar na educação. Petrópolis: Vozes, 1995.

; OSCANYAN, Frederick S.; SHARP, Ann Margaret. Filosofia na sala de aula. São Paulo: Nova Alexandria, 1994.

MURARO, Darcísio Natal. Filosofia para Crianças - uma breve introdução. Disponível em: <http://www.culturainfancia.com.br/portal/index.php?option=com_content\&vie $\mathrm{w}=$ article\&catid=60:filosofia\&id=109:filosofia-para-criancas-uma-breve-introducao\&Itemid=100>. Acesso em: 25 de ago. 2012. 
PLATÃO. Teeteto. Traduçâo Carlos Alberto Nunes. 3• Edição Revisada. Ed. UFPA: Belém- Pará 2001

VERGEZ, André; HUISMAN, Denis. História dos filósofos ilustrada pelos textos. $6^{\mathrm{a}} \mathrm{ed}$. Rio de Janeiro: Freitas Bastos, 1984.

VON ZUBEN, Newton Aquiles. A Filosofia e a condição humana. In: http:// newtonvonzuben.blogspot.com.br/, 2011. Acessado em 22/01/2016.

Recebido em Io mai. 2017 / Aprovado em I8 jun. 2018

\section{Para referenciar este texto:}

LORIERI, M. A.; OLIVEIRA, E. G. Thauma e pensar bem na educação infantil. EccoS - Revista Científica, São Paulo, n. 47, p. 197-213. maio/ago. 2018. Disponível em: <https://doi.org/10.5585/EccoS.n47.7383>. 
